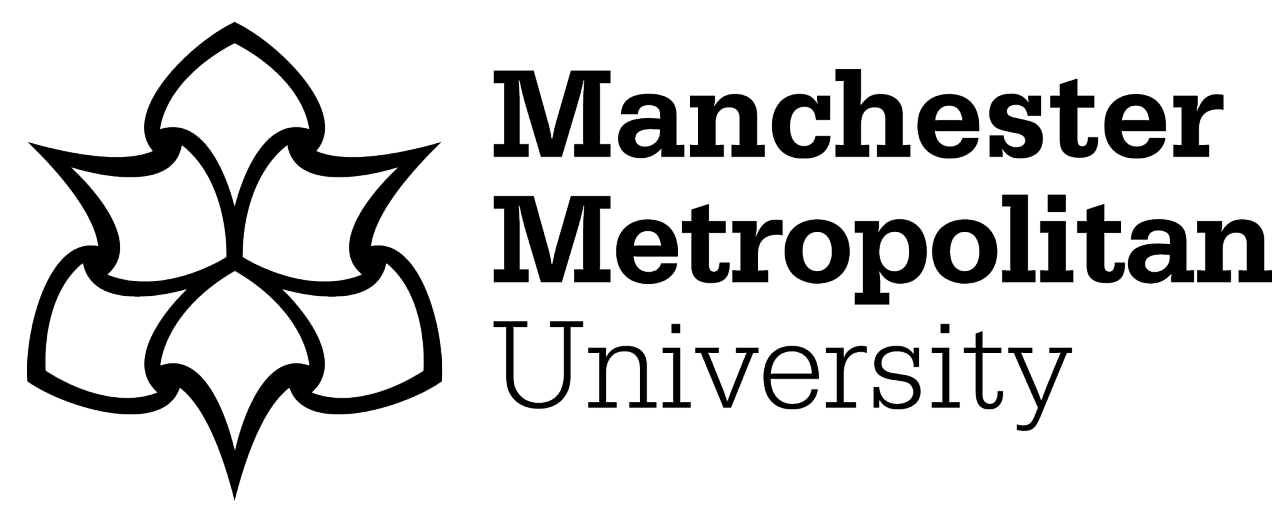

Scimone, Antony, Redfern, James ORCID logoORCID: https://orcid.org/0000-0003-0958-683X, Patiphatpanya, Panudda, Thongtem, Titipun, Ratova, Marina, Kelly, Peter ORCID logoORCID: https://orcid.org/0000-0003-1008-4941 and Verran, Joanna (2021) Development of a rapid method for assessing the efficacy of antibacterial photocatalytic coatings. Talanta, 225. p. 122009. ISSN 0039-9140

Downloaded from: https://e-space.mmu.ac.uk/627025/

Version: Accepted Version

Publisher: Elsevier BV

DOI: https://doi.org/10.1016/j.talanta.2020.122009

Usage rights: Creative Commons: Attribution-Noncommercial-No Derivative Works 4.0

Please cite the published version 


\title{
Development of a rapid method for assessing the efficacy of antibacterial photocatalytic coatings
}

Antony Scimone ${ }^{1}$, James Redfern ${ }^{2}$, Panudda Patiphatpanya ${ }^{3}$, Titipun Thongtem ${ }^{3,4}$, Marina Ratova ${ }^{5}$, Peter Kelly ${ }^{5}$, Joanna Verran ${ }^{1}$.

\footnotetext{
${ }^{1}$ Department of Life Sciences, Faculty of Science and Engineering, Manchester Metropolitan University, Manchester, UK

${ }^{2}$ Department of Natural Sciences, Faculty of Science and Engineering, Manchester Metropolitan University, Manchester, UK

${ }^{3}$ Department of Chemistry, Faculty of Science, Chiang Mai University, Chiang Mai, Thailand

${ }^{4}$ Materials Science Research Center, Faculty of Science, Chiang Mai University, Chiang Mai, Thailand

${ }^{5}$ Surface Engineering Group, Faculty of Science and Engineering, Manchester Metropolitan University, Manchester, UK
}

\begin{abstract}
Visible-light activated photocatalytic coatings may represent an attractive antimicrobial solution in domains such as food, beverage, pharmaceutical, biomedical and wastewater remediation. However, testing methods to determine the antibacterial effects of photocatalytic coatings are limited and require specialist expertise. This paper describes the development of a method that enables rapid screening of coatings for photocatalytic-antibacterial activity. Relying on the ability of viable microorganisms to reduce the dye resazurin from a blue to a pink colour, the method relates the time taken to detect this colour change with number of viable microorganisms.
\end{abstract}

The antibacterial activity of two photocatalytic materials (bismuth oxide and titanium dioxide) were screened against two pathogenic organisms (Escherichia coli and Klebsiella pneumoniae) that represent potential target microorganisms using 
traditional testing and enumeration techniques (BS ISO 27447:2009) and the novel rapid method.

Bismuth oxide showed excellent antibacterial activity under ambient visible light against $E$. coli, but was less effective against $K$. pneumoniae. The rapid method showed excellent agreement with existing tests in terms of number of viable cells recovered. Due to advantages such as low cost, high throughput, and less reliance on microbiological expertise, this method is recommended for researchers seeking an inexpensive first-stage screen for putative photocatalytic-antibacterial coatings.

\section{Keywords}

Antibacterial activity, rapid method, Visible light photocatalysis, titanium dioxide, bismuth oxide, resazurin

\subsection{Introduction}

Microorganisms are ubiquitous. Many species can exist in a viable state for long periods of time, from several hours to several weeks on surfaces and up to several years depending on environmental conditions (Verran, 2002; Kusumaningrum et al., 2003; Liao and Shollenberger, 2003; Wilks et al., 2005; Fuster-Valls et al., 2008; Møretrø et al., 2010; Redfern and Verran, 2017). Pathogenic species with low infectious doses can be transferred from these surfaces many hours after initial contamination, contributing to the spread of disease including antibiotic resistant bacteria and viruses such as influenza and coronavirus (Wilks et al., 2006; Casanova et al., 2010; Greatorex et al., 2011; Gerhardts et al., 2012; PérezRodríguez et al., 2013). Furthermore, with access to nutrients, microorganisms can colonise the surface and form biofilms (Matz et al., 2004; Codd et al., 2005; Driscoll et al., 2007; Banat et al., 2010; Møretrø et al., 2010). Surface contamination and 
subsequent biofilm formation has major implications in certain domains where the hygienic status of the environment is paramount. Industries such as food, beverage, pharmaceutical, biomedical and wastewater remediation all require that microbial populations (bacteria, fungi and viruses) are controlled to prevent the spread of infectious disease, limit horizontal gene transfer, avoid product spoilage, and reduce operating costs (Choi et al., 2007; Simões et al., 2010; Bruscolini et al., 2015; Priha et al., 2015; Redfern and Enright, 2020). Amongst a host of strategies aimed at controlling, reducing or preventing such contamination and colonisation, the application of photocatalytic thin film coatings to surfaces is one approach (Foster et al., 2011).

In recent years, the most commonly reported photocatalyst has been titanium dioxide $\left(\mathrm{TiO}_{2}\right)$. The material first received interest due to Fujishima's discovery of the photocatalytic splitting of water by titanium dioxide (Fujishima and Honda, 1972). Since then, there has been extensive study and development of $\mathrm{TiO}_{2}$ photocatalysts (Fox and Dulay, 1993; Hoffmann et al., 1995; Diebold, 2002; Verran, 2002; Allen et al., 2008; Fujishima et al., 2008; Caballero et al., 2009; Foster et al., 2011; Nakata and Fujishima, 2012; Lang et al., 2014; Low et al., 2017). Research has been focused on $\mathrm{TiO}_{2}$ for three reasons; it has a high stability and activity compared to similar semiconductors, in addition to a low cost (Carp et al., 2004). However, ultraviolet light (UV) is required for activation. UV comprises less than $5 \%$ of total photons of solar light, rendering the photocatalyst relatively inefficient (Dalrymple et al., 2010). Additionally, it is likely that only outdoor coatings would be activated by sunlight at all, as indoor fluorescent lighting contains few UV photons. To be more useful, the photocatalyst must be activated by less energetic photons. Therefore, recent research has focussed on visible-light activated photocatalysts. A common 
strategy to induce visible-light activity for $\mathrm{TiO}_{2}$ has been by doping with other elements (Farahani et al., 2011; Kelly et al., 2014; Ratova et al., 2015; Low et al., 2017; Wu et al., 2017; Yoon et al., 2018).

Alternatively, photocatalysts other than $\mathrm{TiO}_{2}$ with inherent visible light activity have explored. For example, bismuth oxide has high visible-light activity, and also significant photocatalytic-antibacterial properties (Ratova et al., 2018).

Current methods to determine the antibacterial properties of photocatalytic materials can be time-consuming, complex, be affected by changing environmental conditions and require significant microbiological expertise (Redfern et al., 2018a). Therefore, there currently is a need for a more accessible and rapid method to determine the photocatalytic-based antibacterial activity of thin film coatings.

The standardised test method BS ISO 27447:2009 (British Standards Institution, 2009 ) is one of the most commonly used methods to assess the antibacterial activity of a photocatalytic material. While originally designed for UV-activated materials, it has since been adapted for use with visible-light activated photocatalysts (Sadowski et al., 2015). It encompasses the inoculation of coatings with specified numbers of microbial cells in a known volume, followed by irradiation. At pre-determined irradiation times, surviving cells are removed from the surface into a known volume of diluent for enumeration. Since the number of cells is unknown, the enumeration procedure requires the dilution of the cell suspension and the inoculation of agar plates with known volumes (typically $0.1 \mathrm{~mL}$ ) of known dilutions of the suspension. Each cell inoculated onto the agar grows to form one colony, thus after incubation, the number of colonies growing on the agar plates is counted (the dilution which presents the highest countable number of colonies is used), and the number of cells 
in the original suspension is calculated. This method requires competent microbiological expertise (culture maintenance, aseptic technique), and significant amounts of consumable materials (agar plates, diluents, pipettes). Each coating must be tested in the dark (control) as well as under irradiation. The method is also time-consuming, requiring replicate samples and repeat experiments to enable statistical testing of results. For example, testing one coating would require three replicate coupons per sampling time (at least three) for light and dark treatments (total of 18 coupons). At each sampling time, the cell suspension obtained by removal of surviving cells from the surface would be diluted to $10^{-8}$, and each dilution would be inoculated onto two or three agar plates (288 plates required in total for duplicate plates) for incubation - and then the experiment is repeated. An experienced microbiologist would be able to identify any contaminants growing on the agar plates, and would also ensure that the dilution series is accurate (approximately ten-fold reduction in colony counts with each dilution) and that duplicate plates have colony counts that are in agreement.

This procedure can be divided into four main steps: inoculate the presumptive photocatalytic surface with a known number of bacteria in suspension, irradiate the surface for a given time, recover the cells, and then enumerate the colonies produced by the viable recovered bacteria. A pertinent issue with this procedure is the amount of time required; in addition to irradiation time (up to 24 hours) and culture time (18-48 hours), the number of worker hours required to prepare media, inoculate, recover, dilute, spread and count is significant. A faster test, potentially with fewer steps, might encourage more researchers to explore antibacterial properties using a prescribed test, promoting standardisation. 
Colorimetric methods may provide a simpler alternative; such methods may involve the colour change of a dye, linked to the metabolic activity of viable cells. Methylene blue, used for assessing photocatalytic activity, can also be decolourised (reduced) by the metabolic activity of microorganisms. Both methylene blue and resazurin have long been used in the dairy industry as a rapid indicator of the quality of milk (the time taken to decolourise the dye is related to the extent of contamination in the milk and to its quality) (Nixon and Lamb, 1945; Twigg, 1945; Muhammad et al., 2009; Silanikove and Shapiro, 2012).

Resazurin reduces to resorufin by bacterial metabolic co-factors, becoming highly fluorescent (Ex: $550 \mathrm{~nm}$, Em: $583 \mathrm{~nm}$ ) and resulting in a visible colour change from blue to pink (Candeias et al., 1998; González-Pinzón et al., 2012). Unlike some metabolic-based assays such as MTT/XTT, resazurin does not affect the viability of the cells (Barua et al., 2017). The use of resazurin for determination of photocatalytic-antibacterial properties has been shown to be very effective (Lilja et al., 2012; Robertson et al., 2015).

This paper describes a method whereby a photocatalytic surface is inoculated, irradiated, and the remaining viable organisms subsequently recovered in a resazurin growth medium (RGM). The shorter the time taken to detect a colour change, the more microorganisms are present. Comparing this time-to-detection (TTD) to a standard curve can accurately estimate the number of viable cells in the solution. A comparison between the TTD of a photocatalytic surface and a control surface gives some indication of the antibacterial properties of the active surface, should the TTD take longer than the control (or is not attained). In this work, the suspension is incubated whilst concurrently being subject to video recording. Colour change in the suspension, indicative of surviving microorganisms from the surface, is 
indicated on the video footage, and visually determined by rapidly scanning and identifying TDD manually (i.e. when the researcher can see the change of colour). The method can replace the enumeration step of the standard method, reducing the time, cost and expertise required to identify putative antibacterial surfaces and determine their antibacterial efficacy.

In order to demonstrate the effectiveness of the novel detection method, a range of putative photocatalytic antibacterial surface coatings were produced. Visible-light activated bismuth oxide coatings were compared with titanium dioxide. The antibacterial properties of the materials were determined using the current standard test method (BS ISO 27447:2009), and concurrently by the resazurin rapid method to assess how similar the test outcomes are.

\subsection{Methods}

\subsection{Preparation of reagents and maintenance of cell culture}

To prepare the resazurin solution, $0.251 \mathrm{~g}$ resazurin sodium salt (Merck, Gillingham) was mixed with $100 \mathrm{~mL}$ sterile distilled water to make a $10 \mathrm{mM}$ solution. This stock solution was diluted to a final concentration of $0.5 \mathrm{mM}(0.01 \% \mathrm{w} / \mathrm{v})($ VazquezSanchez et al., 2015) and filter sterilized using a $0.2 \mu \mathrm{m}$ filter (PALL, Port Washington). Sterile saline 0.85\%w/v (Saline tablets BR0053, Oxoid, Basingstoke) and sterile nutrient broth (Nutrient broth, CM0001, Oxoid, Basingstoke) were prepared according to manufacturer's instructions. A stock of RGM was then prepared by aseptically combining the three ingredients (Table 1).

Table 1: Concentrations of reagents used to produce RGM.

\begin{tabular}{|c|c|c|}
\hline Reagent & $\begin{array}{c}\text { Percentage by volume, } \\
\%\end{array}$ & Volume in one litre, $\mathrm{mL}$ \\
\hline Sterile $0.85 \% \mathrm{w} / \mathrm{v}$ saline & 89 & 890 \\
\hline
\end{tabular}




\begin{tabular}{|c|c|c|}
\hline Sterile nutrient broth & 10 & 100 \\
$\begin{array}{c}\text { Filtered } 0.5 \mathrm{mM} \\
\text { resazurin solution }\end{array}$ & 1 & 10 \\
\hline
\end{tabular}

The RGM was designed so the 'final' concentration of resazurin would be $5 \mu \mathrm{M}$ $(0.0001 \% \mathrm{w} / \mathrm{v})$, similar to other published studies (e.g. Csepregi et al., 2018). This concentration ensured the use of minimal reagent while maintaining effective microbial detection. The RGM was dispensed aseptically into $100 \mathrm{~mL}$ volumes and maintained at $4{ }^{\circ} \mathrm{C}$ for a maximum of six months.

\subsection{Maintenance and standardisation of microbiological cultures}

Two pathogenic bacterial species used in existing test methods (British Standards Institution, 2009; Mills et al., 2012; Egamberdieva et al., 2017), Escherichia coli 8739 (ATCC $₫ 8739^{\mathrm{TM}}$, American Type Culture Collection, Manassas) and Klebsiella pneumoniae 40602 (Manchester Metropolitan University, Manchester) were selected for this study.

The organisms were stored long-term in a $-80^{\circ} \mathrm{C}$ freezer (Hubálek, 2003; De Paoli, 2005 ) in $1.5 \mathrm{~mL}$ volumes of $30 \%$ glycerol suspension, prepared by combining $300 \mathrm{~g}$ of glycerol (Fisher Scientific, Hampton) with one litre of sterile distilled water. When required, the microorganism was subcultured from the freezer stock by aseptically taking a loopful of frozen material and streaking onto a nutrient agar plate (Oxoid, Basingstoke). The plate was incubated at $37^{\circ} \mathrm{C}$ for 18 hours, and checked for purity. This stock plate was stored in the fridge at $4{ }^{\circ} \mathrm{C}$ and used for assays for up to $4-6$ weeks, after which, a fresh stock plate was produced from the freezer stock.

To carry out microbiological assays, a standardised washed cell suspension was prepared. This enables the inoculation of the test surface with a known number of 
microorganisms. In addition, washing the cells removes residual nutrients (salts, sugars, amino acids, etc.) and by-products formed during the growth of the cells. These nutrients and by-products may have unintended effects on the assays, such as providing additional nutrients leading to additional proliferation of the cells, and acting as preferential or alternative reaction targets for the resazurin dye molecules (or any active antibacterial agents), leading to inaccurate results.

To prepare a standardised washed cell suspension, one colony from the stock plate was inoculated into $10 \mathrm{~mL}$ of fresh sterile nutrient broth and incubated at $37^{\circ} \mathrm{C}$ for 18 hours with shaking at $180 \mathrm{rpm}$. Cells were harvested by centrifugation (2300G, 10 minutes), resuspended in $10 \mathrm{~mL}$ of sterile saline and mixed using a vortex mixer (Rotamixer Vortex-Mixer, HTZ Limited, Croydon) for 10 seconds. The suspension was centrifuged again (2300G, 10 minutes), then resuspended in sterile saline and adjusted to an optical density of 0.9-1.1 at $540 \mathrm{~nm}$ (Jenway $6305 \mathrm{UV} / \mathrm{Visible}$ Spectrophotometer, Chelmsford). This was then diluted 1:10 in sterile saline to make a standardised washed cell suspension of approximately $10^{8} \mathrm{CFU} \mathrm{mL}^{-1}$ (confirmed via ten-fold serial dilution and colony counting).

\subsection{Standard curve}

To calibrate bacterial load against TTD, a curve was constructed. Simulating the method of inoculating surfaces and recovery used in the standard test (British Standards Institution, 2009), without in this case an active antibacterial surface, a washed cell suspension of each organism was prepared. This was diluted 10-fold eight times, thereby providing a range of bacterial concentrations $\left(1 \times 10^{7} \mathrm{CFU} \mathrm{mL} \mathrm{L}^{-1}\right.$ to $1 \times 10^{1} \mathrm{CFU} \mathrm{mL}{ }^{-1}$, assuming the original concentration to be around $1 \times 10^{8} \mathrm{CFU} \mathrm{mL}^{-1}$ ). Sterile glass coupons $(1 \mathrm{~cm} \times 2 \mathrm{~cm})$ were inoculated with either $50 \mu \mathrm{L}$ of each 
dilution (one coupon per dilution) or with sterile saline (as a bacteria-free, noninoculated control, to assess the effect of nutrient broth on the resazurin) in duplicate, thus yielding two biological replicates. A $1 \mathrm{~cm} \times 2 \mathrm{~cm}$ piece of polyethylene (SLS, Nottingham), washed in $70 \%$ ethanol and left to dry in a Class 2 biosafety cabinet (Bio 2+ Class 2 Microbiological Safety Cabinet, Envair Ltd, Haslingden), was gently placed on top of each inoculum (taking care not to spill any inoculum over the edge of the coupons). The covered glass coupons were then immediately and aseptically transferred to $5 \mathrm{~mL}$ sterile plastic containers ('bijou' bottles, SLS, Nottingham) containing $5 \mathrm{~mL}$ of RGM and vortex mixed for $60 \mathrm{~s}$ to remove cells from the surface. To determine the number of viable cells present in the resultant suspension, a 10 -fold serial dilution to $10^{-8}$ was carried out, and the Miles-Misra viable count method was used (Miles et al., 1938; Redfern et al., 2018b; Hickey et al., 2019). Briefly, a fresh sterile nutrient agar plate was divided equally into eight sectors, and $20 \mu \mathrm{L}$ of each dilution aliquoted onto each section in triplicate (thereby reducing the number of agar plates required for the experiment). After the inoculum drops had dried, the plates were inverted and incubated for 12-18 hours, after which the number of colonies was counted and the number of viable cells recovered calculated (the Miles-Misra method enables colony counts to be made using far fewer plates than the (more accurate) $0.1 \mathrm{~mL}$ spread inoculum method described above).

Concurrently, the coupons and polyethylene films were removed from the bijou bottles using sterile forceps. These bottles were then incubated at $37^{\circ} \mathrm{C}$ in an orbital incubator at 180 rpm for 18 hours, whilst being filmed by a video recorder (Victure AC800 Action Camera, Victure). The recorder was set to capture one still image every 5 seconds at a resolution of 1080p, creating date- and time-stamped time- 
lapse footage. The video footage was loaded onto a computer and rapidly scanned (quickly fast-forwarded and rewound using the cursor, described by the term 'scrubbing') using a free commercially available video player (VLC media player, VideoLAN, https://www.videolan.org/). The time (from the video timestamp) of the colour change from blue to pink (detected by eye), occurring as the resazurin was being reduced to resorufin by bacterial metabolic co-factors, was recorded as the TTD (Figure 1).

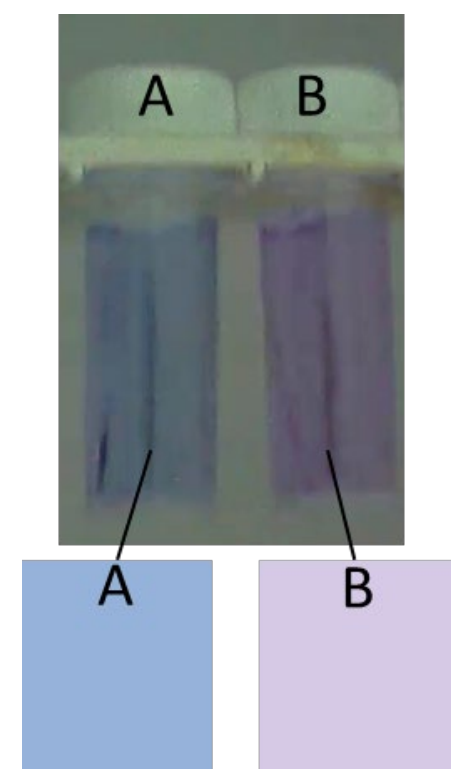

Figure 1: Still image excerpt from the digital camera recording, demonstrating time to detection, i.e., the point when the resazurin was first observed to change colour. The colour of the non-inoculated control sample $(A)$ is compared to the test sample $(B)$ while rapidly scanning through the video recording, to determine colour change by eye.

The TTD was plotted against the corresponding concentration of viable cells. This experiment was repeated three times.

\subsection{Determination of antibacterial activity using both the TTD method and plate}

\section{count method}

To demonstrate the accuracy of the TTD as it related to viable cell counts, and to use the resazurin assay in its intended application, $1 \mathrm{~cm} \times 2 \mathrm{~cm}$ glass coupons were coated with either photocatalytic anatase titanium dioxide $\left(\mathrm{TiO}_{2}\right)$, or photocatalytic 
bismuth oxide $\left(\mathrm{Bi}_{2} \mathrm{O}_{3}\right)$. The coatings were prepared via the magnetron sputter method. The deposition conditions were fully identical to the one described earlier for the deposition of bismuth oxide and titanium dioxide (Ratova et al., 2018), with the exception of the films being deposited onto soda-lime glass slides in this case. For this purpose the glass slides, ultrasonically pre-cleaned in propanol prior to deposition, were mounted on a rotatable substrate holder positioned underneath two magnetrons. The deposition time was $30 \mathrm{~min}$ for each material; the films were postdeposition annealed in air for $30 \mathrm{~min}$ to enable crystal phase development at preidentified temperatures: $400^{\circ} \mathrm{C}$ for bismuth oxide, $600^{\circ} \mathrm{C}$ for titanium dioxide. Following post-thermal treatment bismuth oxide was in the tetragonal $\beta$-phase, while titanium dioxide was in the anatase phase. The properties of the materials were analysed in detail in earlier work and the results can be found elsewhere (Ratova et al., 2017; Ratova et al., 2018).

The antibacterial capabilities of these materials were determined following an adapted BS ISO 27447:2009 (British Standards Institution, 2009) and the rapid TTD method described above. Each coupon was inoculated as previously described in the standard curve protocol with $20 \mu \mathrm{L}$ of $1 \times 10^{6} \mathrm{CFU} \mathrm{mL}^{-1} \mathrm{E}$. coli 8739 , placed in a sterile petri dish, and exposed to ambient visible light irradiation (UV irradiance $<0.01$ $\mathrm{mW} / \mathrm{cm}^{2}$ ) for 0,30 , or 60 minutes. Non-irradiated controls for the photocatalytic surfaces were prepared by wrapping the petri dish in aluminium foil (Aluchef premier foil, Terinex. Bedford) to prevent light ingress. Each experimental condition (surface type and irradiation status) was performed in duplicate, yielding two biological replicates per experimental condition. After the prescribed time, each coupon was transferred to a bijou bottle containing $5 \mathrm{~mL}$ of RGM. This was vortex mixed for sixty seconds to remove cells from the surface. The coupons and polyethylene films were 
removed from the bijou bottles using sterile forceps, and the resultant cell suspensions were enumerated via Miles-Misra viable count in triplicate and estimated via the resazurin method as described above.

Each bottle was monitored during rapid video scanning to identify colour change and determine the TTD. The TTD was then compared to the standard curve using the line of best fit equation to determine the 'estimated' initial concentration. This was compared with the 'counted' viable cell number. These experiments were repeated twice.

\subsection{Statistical Analysis}

Data were analysed for statistically significant differences, relationships and agreements, as appropriate using GraphPad Prism 7 for Windows and IBM SPSS Statistics version 25. Differences between groups were identified using 2-way ANOVA with multiple comparisons. Relationships between variables were investigated using linear regression models. Agreement between measurement methods was assessed using intraclass correlation coefficient analysis. The alpha level was set to 0.05; differences, relationships and agreements were considered significant if $p<0.05$.

\subsection{Results}

There was a very strong statistically significant correlation between the initial inoculum concentration and the time to detect a colour change (TTD) for E. coli $\left(R^{2}=0.985, p<0.001\right.$, Figure 2). 


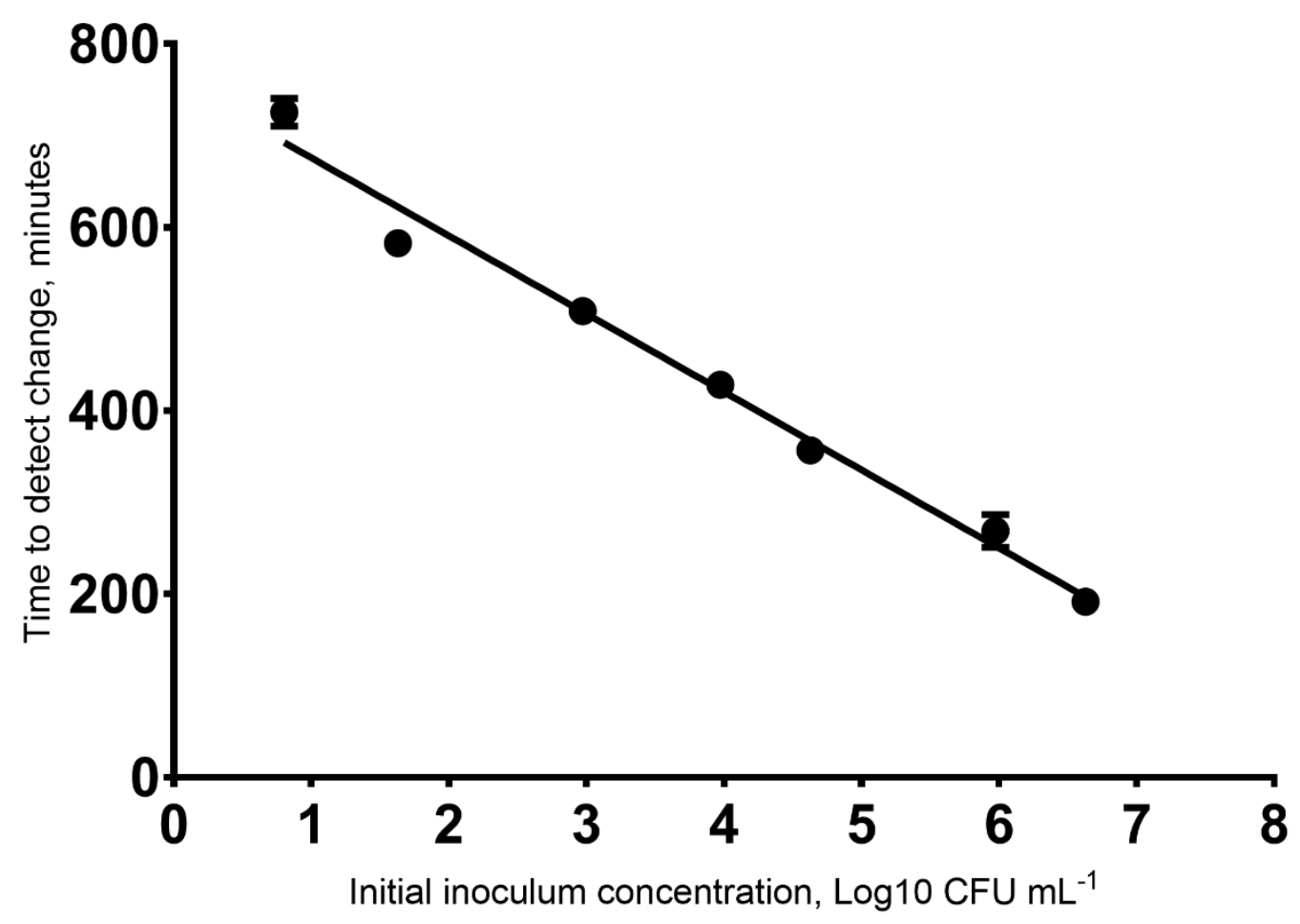

Figure 2: Standard curve of time to detection (TTD) and initial inoculum concentration for E. coli. A negative linear relationship between TTD and initial inoculum concentration was observed $\left(R^{2}=0.985\right.$, $\mathrm{p}<0.001, \mathrm{n}=6)$.

A similar result was observed for the $K$. pneumoniae $\left(R^{2}=0.99, p<0.001\right.$, Figure 3$)$.

No change in colour was observed in the bacteria-free controls within 18 hours. 


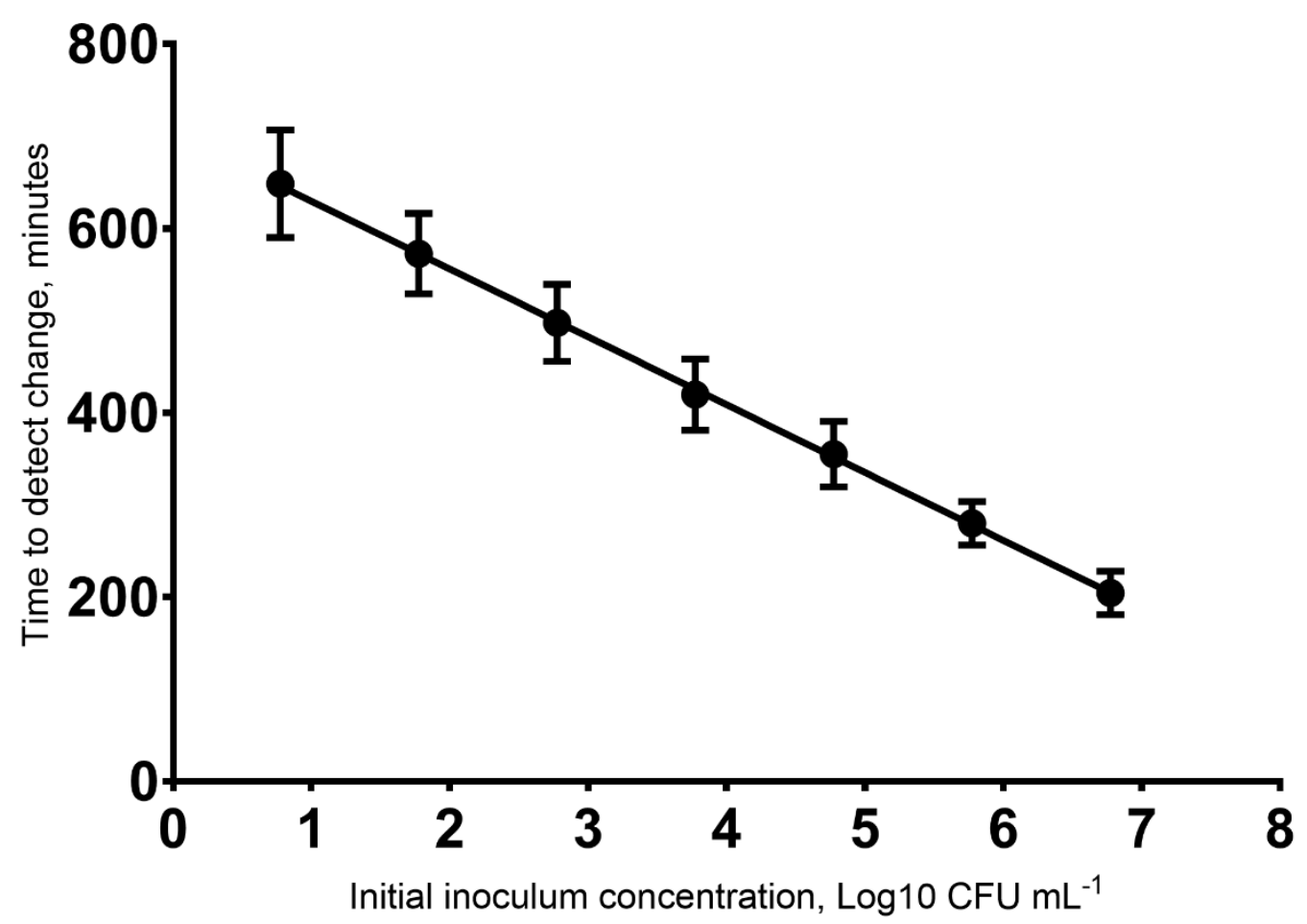

Figure 3: Standard curve of time to detection (TTD) and initial inoculum concentration for $K$. pneumonia. A negative linear relationship between TTD and initial inoculum concentration was observed $\left(R^{2}=0.99, p<0.001, n=6\right)$.

These standard curves were subsequently used to estimate the number of viable cells recovered from the coated test surfaces. Irradiated bismuth oxide coatings reduced the number of viable $E$. coli by 1.2 Log10 CFU mL-1 after 30 minutes $(p<0.001)$, and 2.6 Log10 CFU mL-1 after 60 minutes ( $p<0.001)$ (Figure 4A). A small but significant reduction of $0.85 \mathrm{Log} 10 \mathrm{CFU} \mathrm{mL}-1$ in the number of viable $K$. pneumoniae on irradiated bismuth oxide was observed after 60 minutes $(p<0.001)$ (Figure 4B). Similar small reductions in viability were observed after sixty minutes exposure to the irradiated titania for both E. coli $\left(0.71\right.$ Log10 CFU mL $\left.{ }^{-1}, \mathrm{p}<0.001\right)$ and $K$. pneumoniae (0.49 Log10 CFU mL $\left.{ }^{-1}, \mathrm{p}=0.03\right)$. In addition, there was a reduction of $0.57 \log 10 \mathrm{CFU} \mathrm{mL}^{-1}$ of $E$. coli exposed to non-irradiated bismuth oxide 
for sixty minutes $(p<0.001)$. No other antibacterial effects were observed for the ambient irradiated titanium dioxide coatings or dark controls.
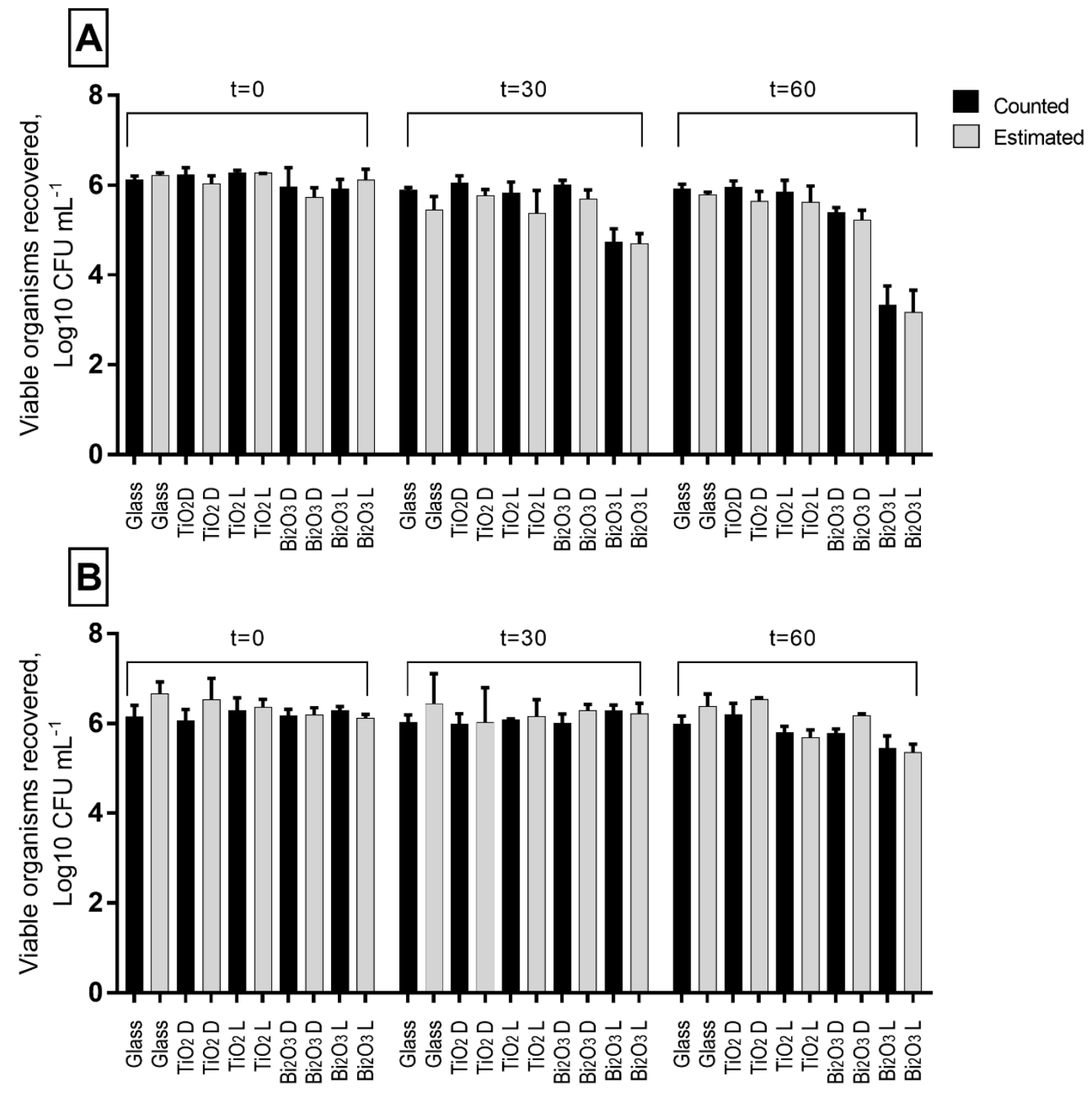

Figure 4: Counted (black) and estimated (by TTD - grey) viable cells for each experimental condition for $\mathrm{A}$ ) $\mathrm{E}$. coli and $\mathrm{B}$ ) $\mathrm{K}$. pneumoniae. $\mathrm{TiO}_{2}=$ titanium dioxide. $\mathrm{Bi}_{2} \mathrm{O}_{3}=$ bismuth oxide. $\mathrm{D}=$ dark control. $\mathrm{L}=$ ambient light irradiation. $\mathrm{N}=4$.

In terms of agreement between the methods, there were no significant differences between the mean number of viable cells recovered reported via the viable count method and estimated method for each experimental condition. To assess further the agreement and relationship between methods, the results were combined, and a 
correlation analysis was performed. A significant strong correlation was noted between bacterial load reported via viable count and estimated method (Figure 5) $(r=0.64, p<0.001)$.

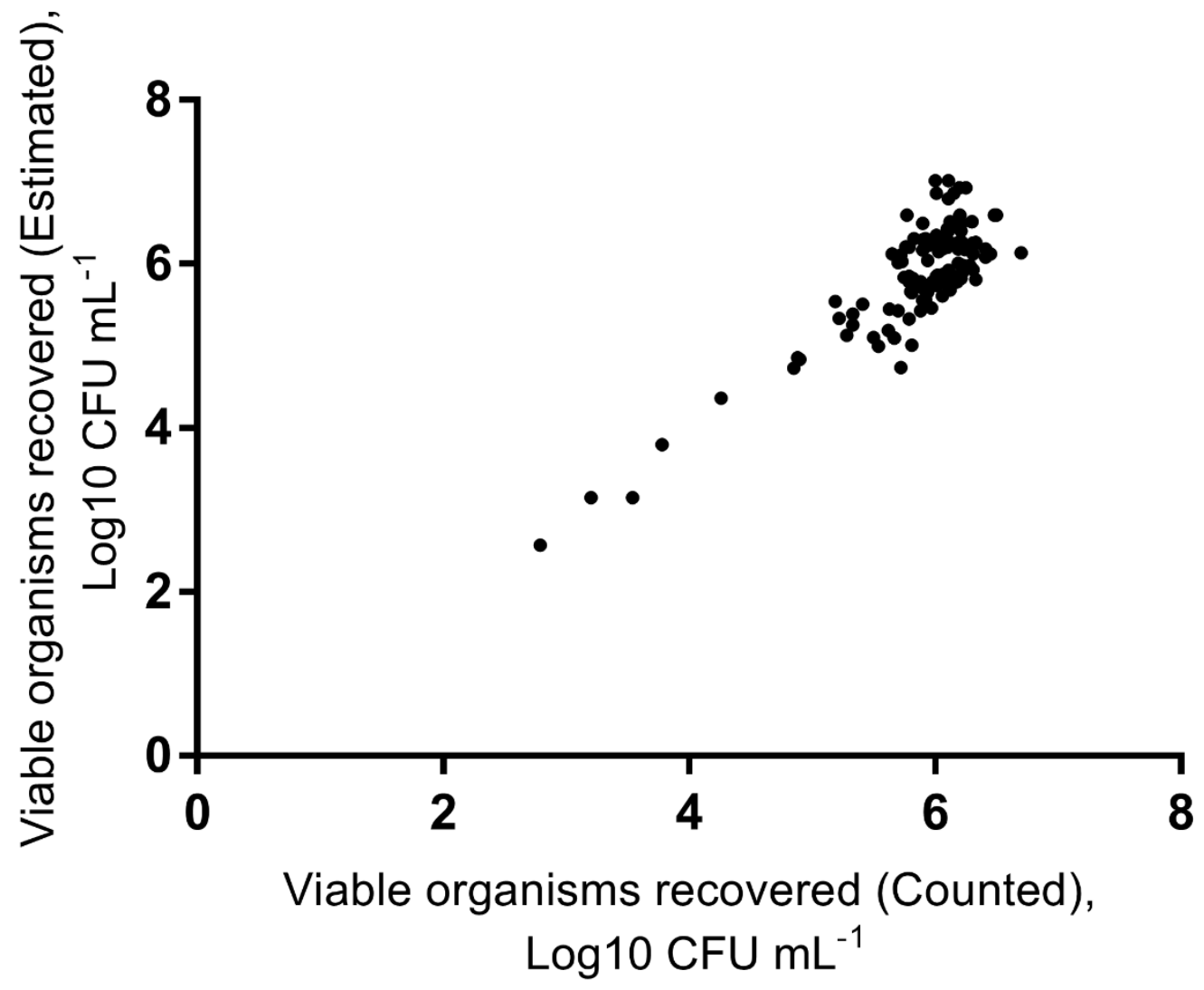

Figure 5: Correlation between counting and estimating the bacterial load $(r=0.64, p<0.001, n=120)$. There was a strong correlation indicating that both methods were able to detect an increase in bacterial load.

As correlation analysis identifies the relationship between the methods, a BlandAltman plot was used to assess the differences between the methods, identify bias, and construct limits of agreement (Bland and Altman, 1986; Giavarina, 2015).

The Bland-Altman analysis (Figure 6) showed that the rapid estimated method had a mean difference from the counted method (bias) of 0.019 Log10 CFU mL-1, with $95 \%$ limits of agreement from -0.72 to $0.72 \log 10 \mathrm{CFU} \mathrm{mL}$. . This indicates that for $95 \%$ of cases, the number of recovered viable cells reported by the resazurin rapid 
estimated method may be between 0.72 Log10 CFU mL-1 below and 0.72 Log10

CFU $\mathrm{mL}^{-1}$ above the result reported by a Miles-Misra viable count.

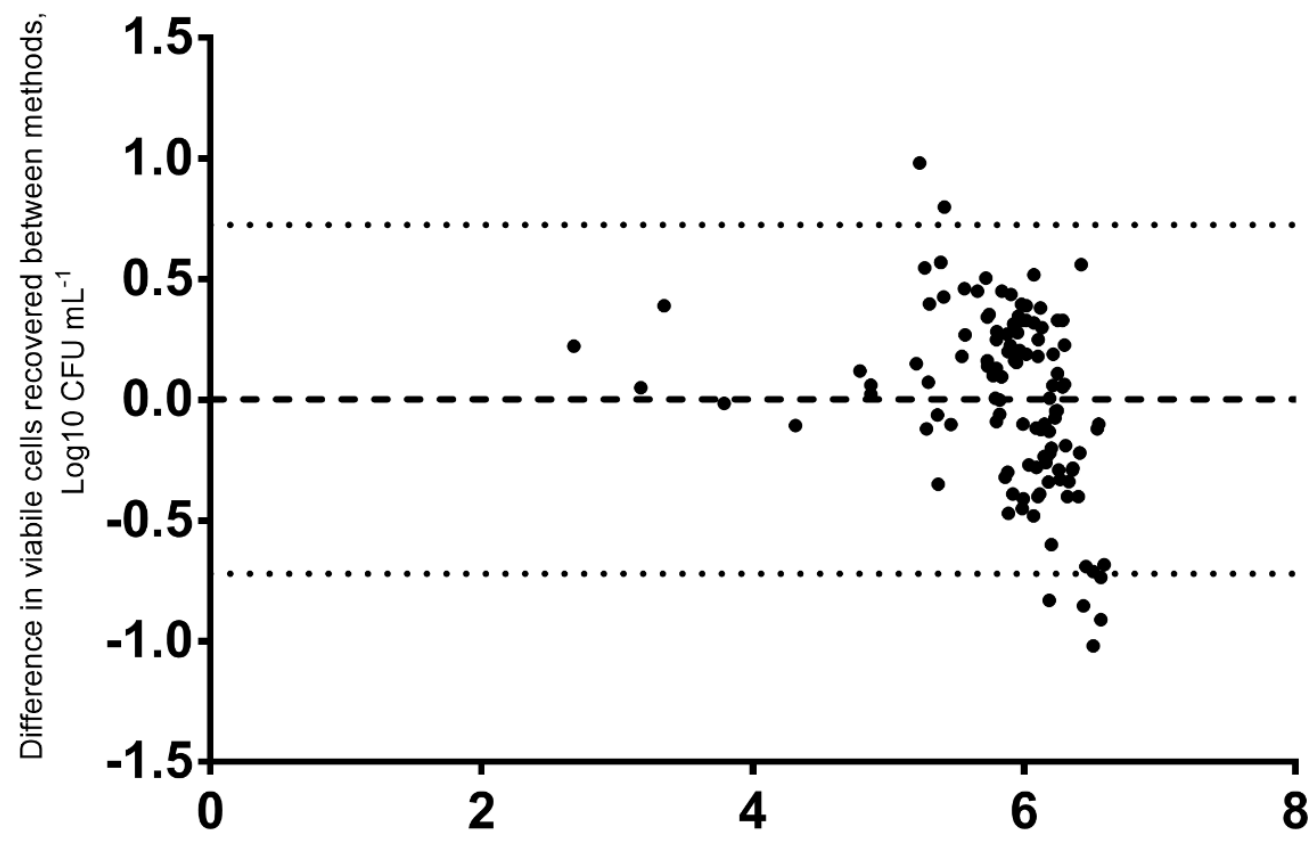

Viable cells recovered (mean of methods), Log10 CFU mL-1

Figure 6: Bland-Altman analysis of the difference between counted and estimated measurements. Dashed line indicates mean difference (bias) between measurements $\left(0.019\right.$ Log $\left.10 \mathrm{CFU} \mathrm{mL}^{-1}\right)$. Dotted lines represent $95 \%$ limits of agreement $(-0.72$ to 0.72 Log10 CFU mL-1). The negligible bias and narrow limits of agreement indicate excellent agreement between methods. $\mathrm{N}=120$.

Absolute agreement of the measurements obtained by each method was determined by intraclass correlation coefficient analysis. An intraclass coefficient of 0.846 (95\% $\mathrm{Cl}[0.786,0.890], \mathrm{p}<0.001)$ indicated excellent agreement between methods.

\subsection{Discussion}

Photocatalytic processes have been frequently reported as having the potential for inexpensive and sustainable inactivation of microbial pathogenic species.

Applications where they may be useful include hospital environments (Reid et al., 2018; Priyadarshini et al., 2020), decontamination and remediation of water 
(Ioannou-Ttofa et al., 2019; Oliveira et al., 2019; Redfern and Enright, 2020), highfrequency contact surfaces (Kim et al., 2018), and in air purification systems (Mohamed and Awad, 2020). However, the translation of these reports to real-world systems may be limited by several factors. Although the antibacterial properties of titanium dioxide, the most commonly used photocatalyst (Chong et al., 2010; Ratova et al., 2018), have been extensively utilised in recent years (Das et al., 2017), this photocatalyst may have a limited application in the intended environments due to the requirement for a UV source to activate the material. To realise the potential for photocatalytic inactivation of nosocomial, water, and skin pathogens, the material must be able to be activated by visible light, preferably solar or ambient fluorescent light (Caballero et al., 2009; Chong et al., 2010; Pelaez et al., 2012). In comparison to papers focusing on titanium dioxide, there are few reports of the antibacterial properties of visible light-activated photocatalysts.

In this study, the titanium dioxide was not activated by the ambient light due to its large bandgap of $3.20 \mathrm{eV}$ (Ratova et al., 2020), and therefore was unable to reduce the microbial load of either E. coli or K. pneumoniae by a clinically meaningful amount. The bismuth oxide on the other hand, with a much narrower reported bandgap of $2.40 \mathrm{eV}$ (Ratova et al., 2018), was able to reduce the microbial load of $E$. coli by $93.7 \%$ after thirty minutes, and by $99.7 \%$ after sixty minutes, after exposure to ambient light. It is likely that different organisms may have different responses to the photocatalyst. Therefore, the intended application must be considered for photocatalytic antibacterial coatings, and test conditions should always closely emulate the intended application wherever possible (Redfern et al., 2018a). Although photocatalytic antibacterial coatings provide a promising avenue for passive disinfection of surfaces, and broad spectrum activity has been demonstrated against 
several medically relevant bacterial such as methicillin-resistant Staphylococcus aureus (MRSA), vancomycin-resistant Enterococcus faecalis, penicillin-resistant Streptococcus pneumoniae, and multidrug-resistant Pseudomonas aeruginosa (Nakano et al., 2013), the universality of the technology as an antibacterial cannot yet be claimed.

Results from the rapid estimation method gave excellent agreement with traditional counting methods. The construction of the standard curve demonstrated that cell concentration has a linear relationship with TTD of metabolic change of resazurin, with a higher concentration of initial inoculum resulting in a shorter TTD. This is due to each cell having a specific metabolic potential, with two identical cells having a combined metabolic capacity of twice the single cell and so on. While cells from the same strain and culture may have variation in terms of metabolic capacity (Nikolic et al., 2017), the relationship between Log10 inoculum concentration (cell number) and TTD (metabolic capacity) was linear. In other words, as TTD is related to the metabolic potential of the bacterial community present, it follows that the linear relationship observed is actually a representation of the metabolic needs of the bacterial community. Therefore, given similar cells, the number of bacteria present is represented; higher concentrations of cells lead to a higher concentration of cofactors capable of reducing resazurin to resorufin. This standard curve experiment should be repeated for different strains of interest depending on the intended application. Therefore, future work could include the development of several standard curves for typical model and applied organisms of interest. These could include relevant Gram-positive nosocomial pathogens (which were not included in this study) such as multi-drug resistant Staphylococcus aureus (MRSA) and 
vancomycin-resistant enterococcus (Enterococcus faecium and Enterococcus faecalis) (Kim et al., 2018).

In addition to the excellent agreement reported between methods, the rapid method represents a significantly more accessible test, requiring less microbiological expertise (including reduced requirement for dedicated microbiology laboratory space) and laboratory plasticware and reagents (diluent, agar, petri dishes, etc.). Importantly, the time taken to performed the test is reduced compared to standard culture-and-count methods - in this study, bacterial concentrations as low as $1 \times 10^{1}$ CFU mL ${ }^{-1}$ were able to be detected within 10-12 hours. Furthermore, this time reduction includes less time 'at the bench' for the user (facilitated by the reduction in diluting and plating from individual samples), highlighting further improvements in efficiency.

The use of resazurin for enumeration of microbial cells has been noted by other authors (González-Pinzón et al., 2012; Lilja et al., 2012; An et al., 2020). In other studies, however, usually the fluorescence is monitored. While more sensitive than assessment of colour or absorbance monitoring (Rampersad, 2012), fluorescence monitoring systems require the use of more specialised equipment and so are less suitable for adoption by surface engineering or non-specialist groups, and therefore as rapid testing technique for assessment of antibacterial activity of photocatalysts. Furthermore, it has been shown that components of growth media can themselves cause increases in fluorescence, even in the absence of cells (Munshi et al., 2014), contributing to potential measurement errors. By instead using an easily determined colour change with a dilute growth medium, the process is simplified, reducing potential measurement error. It has shown good correlation with other metabolic assay tests such as XTT/MTT (Hamid et al., 2004; Pettit et al., 2005; Peeters et al., 
2008), whilst having considerable improvements such as reduced toxicity (to both the operator and sample cells), reduced costs, reduced time to perform the test and fewer steps, improving usability and making it an attractive alternative for microbial enumeration. This resazurin TTD method is useful for first stage screening of antibacterial surfaces as a replacement for the costly and time-consuming enumeration step, which also requires some element of technical expertise and precision. The chief advantage of this test is its accessibility for non-specialists (requiring less microbiological expertise and experience) and low cost. It can identify reductions in cell number caused by an intervention using a simple redox dye and assessing a colour change by eye, a method that agrees well with established culture-and-count techniques. The inclusion of a digital automated camera with recording functions make this test semi-automated and enables increased throughput, as well as providing a data record. This initial screen enables selection of candidate antibacterial surfaces for more detailed investigation and quantitative testing via established standardised methods.

An important aspect to consider with reporting photocatalytic inactivation of microorganisms is accurate comparison between authors. Key variables to consider such as temperature, humidity and irradiation parameters, the inoculation size and vehicle, and recovery medium should be considered, along with the choice of control samples and number of test sample. As with many microbiological testing methods, transparency in reporting the methods is paramount (Parker et al., 2018). Small differences in experimental variables can affect the overall number of viable cells recovered, both by affecting the viability of the cells (Redfern and Verran, 2017) and by affecting recovery parameters (Verran et al., 2010), thus changing the photocatalytic-antibacterial efficacy reported (Foster et al., 2010). 
A key advantage of this method is that the time and cost of screening candidate materials is reduced. Therefore, if desired the number of experimental conditions can be increased with less investment than the culture-and-count method. For example, the number of exposure times investigated can be increased, providing a more detailed picture of the antibacterial properties of the material. It is vital that, if a photocatalyst is to be successfully employed, it must inactivate the microbial community quickly. This is because the reactive oxygen species generated during photocatalysis cause the bacterial cells to exhibit a stress or SOS response. This coordinated response may upregulate certain genes that mediate efflux pumps, mutation rate, biofilm formation, and horizontal gene transfer - all of which are elements that may contribute to antibacterial resistance (Redfern and Enright, 2020; Yin et al., 2020). By including more exposure times, it can be ascertained that a candidate material exhibits rapid inactivation of microorganisms, in addition to longterm activity that may help prevent colonisation of the surface.

Recent publications have posited that antibacterial surface materials may assist the reduction in spread of multidrug-resistant bacteria (Ansari et al., 2020). The ability for surface engineers to select candidate antibacterial surfaces more quickly has never been more pressing. The method presented here is rapid, requires no specialised equipment and can provide high-throughput quantitative results that can aid surface engineers assess the photocatalytic-antibacterial activity of candidate surfaces. It is hoped that this method may represent a stepping stone for authors to screen and select promising candidate surfaces for further analysis (such as more objective determination of the photocatalytic-antibacterial properties using BS ISO 27447:2009, and investigations into bacterial adhesion and retention), helping to 
address ongoing global issues regarding antimicrobial resistance, water remediation, and spread of infectious disease.

\subsection{Conclusion}

In this paper, it was demonstrated that the number of viable cells estimated by the resazurin time-to-detection method was equivalent to the number of viable cells counted via a total count method, in the context of determining the antibacterial properties of a photocatalytic surface coating. The advantages of this method include low cost, high throughput, and no reliance on specialised equipment or extensive microbiological expertise. Therefore, the use of this method is recommended for researchers seeking an inexpensive first-stage screen for putative photocatalyticantibacterial coatings.

Conflicts of interest: There are no conflicts to declare.

\subsection{References}

Allen, N. S., Edge, M., Verran, J., Stratton, J., Maltby, J. and Bygott, C. (2008) 'Photocatalytic Titania Based Surfaces: Environmental Benefits.' Polymer Degradation and Stability, 93(9), pp. 1632-1646.

An, X. S., Zuo, P. and Ye, B. C. (2020) 'A single cell droplet microfluidic system for quantitative determination of food-borne pathogens.' Talanta, 209, p. 6.

Ansari, M. A., Albetran, H. M., Alheshibri, M. H., Timoumi, A., Algarou, N. A., Akhtar, S., Slimani, Y., Almessiere, M. A., Alahmari, F. S., Baykal, A. and Low, I. M. (2020) 'Synthesis of Electrospun $\mathrm{TiO}_{2}$ Nanofibers and Characterization of Their Antibacterial and Antibiofilm Potential against Gram-Positive and Gram-Negative Bacteria.' Antibiotics-Basel, 9(9), p. 15.

Banat, I. M., Franzetti, A., Gandolfi, I., Bestetti, G., Martinotti, M. G., Fracchia, L., Smyth, T. J. and Marchant, R. (2010) 'Microbial Biosurfactants Production, Applications and Future Potential.' Applied Microbiology and Biotechnology, 87(2), pp. 427-444.

Barua, P., You, M. P., Bayliss, K., Lanoiselet, V. and Barbetti, M. J. (2017) 'A rapid and miniaturized system using Alamar blue to assess fungal spore viability: implications for biosecurity.' European Journal of Plant Pathology, 148(1), pp. 139150. 
Bland, J. and Altman, D. (1986) 'Statistical Methods for Assessing Agreement Between Two Methods of Clinical Measurement.' The Lancet, 327(8476), pp. 307310.

British Standards Institution. (2009) BS ISO 27447:2009 - Fine ceramics (advanced ceramics, advanced technical ceramics) - Test method for antibacterial activity of semiconducting photocatalytic materials.

Bruscolini, F., Paolucci, D., Rosini, V., Sabatini, L., Andreozzi, E. and Pianetti, A. (2015) 'Evaluation of Ultraviolet Irradiation Efficacy in an Automated System for the Aseptic Compounding Using Challenge Test.' International Journal for Quality in Health Care, 27(5), pp. 412-417.

Caballero, L., Whitehead, K. A., Allen, N. S. and Verran, J. (2009) 'Inactivation of Escherichia coli on Immobilized $\mathrm{TiO}_{2}$ Using Fluorescent Light.' Journal of Photochemistry and Photobiology A: Chemistry, 202(2-3), pp. 92-98.

Candeias, L. P., MacFarlane, D. P. S., McWhinnie, S. L. W., Maidwell, N. L., Roeschlaub, C. A., Sammes, P. G. and Whittlesey, R. (1998) 'The Catalysed NADH Reduction of Resazurin to Resorufin.' Journal of the Chemical Society, Perkin Transactions 2, (11), pp. 2333-2334.

Carp, O., Huisman, C. L. and Reller, A. (2004) 'Photoinduced Reactivity of Titanium Dioxide.' Progress in Solid State Chemistry, 32(1-2), pp. 33-177.

Casanova, L. M., Jeon, S., Rutala, W. A., Weber, D. J. and Sobsey, M. D. (2010) 'Effects of air temperature and relative humidity on coronavirus survival on surfaces.' Appl Environ Microbiol, 76(9), pp. 2712-2717.

Choi, H., Stathatos, E. and Dionysiou, D. D. (2007) 'Photocatalytic $\mathrm{TiO}_{2}$ Films and Membranes for the Development of Efficient Wastewater Treatment and Reuse Systems.' Desalination, 202(1), pp. 199-206.

Chong, M. N., Jin, B., Chow, C. W. and Saint, C. (2010) 'Recent developments in photocatalytic water treatment technology: a review.' Water Research, 44(10), pp. 2997-3027.

Codd, G. A., Morrison, L. F. and Metcalf, J. S. (2005) 'Cyanobacterial Toxins: Risk Management for Health Protection.' Toxicology and Applied Pharmacology, 203(3), pp. 264-272.

Csepregi, R., Lemli, B., Kunsági-Máté, S., Szente, L., Kőszegi, T., Németi, B. and Poór, M. (2018) 'Complex Formation of Resorufin and Resazurin with BCyclodextrins: Can Cyclodextrins Interfere with a Resazurin Cell Viability Assay?' Molecules 23(2), p. 382.

Dalrymple, O. K., Stefanakos, E., Trotz, M. A. and Goswami, D. Y. (2010) 'A Review of the Mechanisms and Modeling of Photocatalytic Disinfection.' Applied Catalysis B: Environmental, 98(1-2), pp. 27-38. 
Das, R., Vecitis, C. D., Schulze, A., Cao, B., Ismail, A. F., Lu, X. B., Chen, J. P. and Ramakrishna, S. (2017) 'Recent advances in nanomaterials for water protection and monitoring.' Chemical Society Reviews, 46(22), pp. 6946-7020.

De Paoli, P. (2005) 'Bio-Banking in Microbiology: from Sample Collection to Epidemiology, Diagnosis and Research.' FEMS Microbiology Reviews, 29(5), pp. 897-910.

Diebold, U. (2002) 'The Surface Science of Titanium Dioxide.' Surface Science Reports, 48(1), pp. 53-229.

Driscoll, J. A., Brody, S. L. and Kollef, M. H. (2007) 'The Epidemiology, Pathogenesis and Treatment of Pseudomonas aeruginosa Infections.' Drugs, 67(3), pp. 351-368.

Egamberdieva, D., Wirth, S., Behrendt, U., Ahmad, P. and Berg, G. (2017) 'Antimicrobial Activity of Medicinal Plants Correlates with the Proportion of Antagonistic Endophytes.' Frontiers in Microbiology, 8, p. 199.

Farahani, N., Kelly, P. J., West, G., Ratova, M., Hill, C. and Vishnyakov, V. (2011) 'Photocatalytic Activity of Reactively Sputtered and Directly Sputtered Titania Coatings.' Thin Solid Films, 520(5), pp. 1464-1469.

Foster, H. A., Ditta, I. B., Varghese, S. and Steele, A. (2011) 'Photocatalytic Disinfection Using Titanium Dioxide: Spectrum and Mechanism of Antimicrobial Activity.' Applied Microbiology and Biotechnology, 90(6), pp. 1847-1868.

Foster, H. A., Sheel, D. W., Sheel, P., Evans, P., Varghese, S., Rutschke, N. and Yates, H. M. (2010) 'Antimicrobial Activity of Titania/Silver and Titania/Copper Films Prepared by CVD.' Journal of Photochemistry and Photobiology A: Chemistry, 216(23), pp. 283-289.

Fox, M. A. and Dulay, M. T. (1993) 'Heterogeneous Photocatalysis.' Chemical Reviews, 93(1), pp. 341-357.

Fujishima, A. and Honda, K. (1972) 'Electrochemical Photolysis of Water at a Semiconductor Electrode.' Nature, 238(5358), pp. 37-38.

Fujishima, A., Zhang, X. and Tryk, D. (2008) ' $\mathrm{TiO}_{2}$ Photocatalysis and Related Surface Phenomena.' Surface Science Reports, 63(12), pp. 515-582.

Fuster-Valls, N., Hernández-Herrero, M., Marín-de-Mateo, M. and Rodríguez-Jerez, J. J. (2008) 'Effect of Different Environmental Conditions on the Bacteria Survival on Stainless Steel Surfaces.' Food Control, 19(3), pp. 308-314.

Gerhardts, A., Hammer, T. R., Balluff, C., Mucha, H. and Hoefer, D. (2012) 'A Model of the Transmission of Micro-Organisms in a Public Setting and its Correlation to Pathogen Infection Risks.' Journal of Applied Microbiology, 112(3), pp. 614-621.

Giavarina, D. (2015) 'Understanding Bland Altman analysis.' Biochemia Medica, 25(2), pp. 141-151. 
González-Pinzón, R., Haggerty, R. and Myrold, D. D. (2012) 'Measuring Aerobic Respiration in Stream Ecosystems Using the Resazurin-Resorufin System.' Journal of Geophysical Research: Biogeosciences, 117(G00N06), pp. 1-10.

Greatorex, J. S., Digard, P., Curran, M. D., Moynihan, R., Wensley, H., Wreghitt, T., Varsani, H., Garcia, F., Enstone, J. and Nguyen-Van-Tam, J. S. (2011) 'Survival of influenza $A(\mathrm{H} 1 \mathrm{~N} 1)$ on materials found in households: implications for infection control.' PLoS One, 6(11), p. e27932.

Hamid, R., Rotshteyn, Y., Rabadi, L., Parikh, R. and Bullock, P. (2004) 'Comparison of alamar blue and MTT assays for high through-put screening.' Toxicology in Vitro, 18(5), pp. 703-710.

Hickey, N. A., Whitehead, K. A., Shalamanova, L., Butler, J. A. and Taylor, R. L. (2019) 'A novel microbiological medium for the growth of periodontitis associated pathogens.' Journal of Microbiological Methods, 163, p. 105647.

Hoffmann, M. R., Martin, S. T., Choi, W. and Bahnemann, D. W. (1995)

'Environmental Applications of Semiconductor Photocatalysis.' Chemical Reviews, 95(1), pp. 69-96.

Hubálek, Z. (2003) 'Protectants Used in the Cryopreservation of Microorganisms.' Cryobiology, 46(3), pp. 205-229.

Ioannou-Ttofa, L., Raj, S., Prakash, H. and Fatta-Kassinos, D. (2019) 'Solar photoFenton oxidation for the removal of ampicillin, total cultivable and resistant $\mathrm{E}$. coli and ecotoxicity from secondary-treated wastewater effluents.' Chemical Engineering Journal, 355, pp. 91-102.

Kelly, P. J., West, G. T., Ratova, M., Fisher, L., Ostovarpour, S. and Verran, J. (2014) 'Structural Formation and Photocatalytic Activity of Magnetron Sputtered Titania and Doped-Titania Coatings.' Molecules, 19(10), pp. 16327-16348.

Kim, M. H., Lee, S. G., Kim, K. S., Heo, Y. J., Oh, J. E. and Jeong, S. J. (2018) 'Environmental disinfection with photocatalyst as an adjunctive measure to control transmission of methicillin-resistant Staphylococcus aureus: a prospective cohort study in a high-incidence setting.' BMC Infectious Diseases, 18, p. 9.

Kusumaningrum, H. D., Riboldi, G., Hazeleger, W. C. and Beumer, R. R. (2003) 'Survival of Foodborne Pathogens on Stainless Steel Surfaces and CrossContamination to Foods.' International Journal of Food Microbiology, 85(3), pp. 227236.

Lang, X. J., Chen, X. D. and Zhao, J. C. (2014) 'Heterogeneous Visible Light Photocatalysis for Selective Organic Transformations.' Chemical Society Reviews, 43(1), pp. 473-486.

Liao, C. H. and Shollenberger, L. M. (2003) 'Survivability and Long-Term Preservation of Bacteria in Water and in Phosphate-Buffered Saline.' Letters in Applied Microbiology, 37(1), pp. 45-50. 
Lilja, M., Forsgren, J., Welch, K., Astrand, M., Engqvist, H. and Strømme, M. (2012) 'Photocatalytic and Antimicrobial Properties of Surgical Implant Coatings of Titanium Dioxide Deposited Though Cathodic Arc Evaporation.' Biotechnology Letters, 34(12), pp. 2299-2305.

Low, J. X., Cheng, B. and Yu, J. G. (2017) 'Surface Modification and Enhanced Photocatalytic $\mathrm{CO}_{2}$ Reduction Performance of $\mathrm{TiO}_{2}$ : A Review.' Applied Surface Science, 392, pp. 658-686.

Matz, C., Bergfeld, T., Rice, S. A. and Kjelleberg, S. (2004) 'Microcolonies, Quorum Sensing and Cytotoxicity Determine the Survival of Pseudomonas aeruginosa Biofilms Exposed to Protozoan Grazing.' Environmental Microbiology, 6(3), pp. 218226.

Miles, A. A., Misra, S. S. and Irwin, J. O. (1938) 'The Estimation of the Bactericidal Power of the Blood.' The Journal of Hygiene, 38(6), pp. 732-749.

Mills, A., Hill, C. and Robertson, P. K. J. (2012) 'Overview of the Current ISO Tests for Photocatalytic Materials.' Journal of Photochemistry and Photobiology A: Chemistry, 237, pp. 7-23.

Mohamed, E. F. and Awad, G. (2020) 'Photodegradation of gaseous toluene and disinfection of airborne microorganisms from polluted air using immobilized TiO2 nanoparticle photocatalyst-based filter.' Environmental Science and Pollution Research, p. 11.

Møretrø, T., Heir, E., Mo, K. R., Habimana, O., Abdelgani, A. and Langsrud, S. (2010) 'Factors Affecting Survival of Shigatoxin-Producing Escherichia coli on Abiotic Surfaces.' International Journal of Food Microbiology, 138(1-2), pp. 71-77.

Muhammad, K., Altaf, I., Hanif, A., Anjum, A. A. and Tipu, M. Y. (2009) 'Monitoring the Hygienic Status of Raw Milk Marketed in Lahore City, Pakistan.' Journal of Animal and Plant Sciences, 19(2), pp. 74-77.

Munshi, S., Twining, R. C. and Dahl, R. (2014) 'Alamar Blue Reagent Interacts with Cell-Culture Media Giving Different Fluorescence Over Time: Potential for False Positives.' Journal of Pharmacological and Toxicological Methods, 70(2), pp. 195198.

Nakano, R., Hara, M., Ishiguro, H., Yao, Y. Y., Ochiai, T., Nakata, K., Murakami, T., Kajioka, J., Sunada, K., Hashimoto, K., Fujishima, A. and Kubota, Y. (2013) 'Broad Spectrum Microbicidal Activity of Photocatalysis by TiO2.' Catalysts, 3(1), pp. 310323.

Nakata, K. and Fujishima, A. (2012) ' $\mathrm{TiO}_{2}$ Photocatalysis: Design and Applications.' Journal of Photochemistry and Photobiology C: Photochemistry Reviews, 13(3), pp. 169-189.

Nikolic, N., Schreiber, F., Dal Co, A., Kiviet, D. J., Bergmiller, T., Littmann, S., Kuypers, M. M. M. and Ackermann, M. (2017) 'Cell-to-Cell Variation and Specialization in Sugar Metabolism in Clonal Bacterial Populations.' PLOS Genetics, 13(12), p. e1007122. 
Nixon, M. C. and Lamb, A. B. (1945) 'Resazurin Test for Grading Raw Milk.'

Canadian Journal of Comparative Medicine and Veterinary Science, 9(1), pp. 18-23.

Oliveira, A. G., Andrade, J. d. L., Montanha, M. C., Lima, S. M., Andrade, L. H. d. C., Winkler Hechenleitner, A. A., Pineda, E. A. G. and Oliveira, D. M. F. d. (2019) 'Decontamination and disinfection of wastewater by photocatalysis under UV/visible light using nano-catalysts based on Ca-doped ZnO.' Journal of Environmental Management, 240, pp. 485-493.

Parker, A. E., Hamilton, M. A. and Goeres, D. M. (2018) 'Reproducibility of Antimicrobial Test Methods.' Scientific Reports, 8(1), p. 12531.

Peeters, E., Nelis, H. J. and Coenye, T. (2008) 'Comparison of Multiple Methods for Quantification of Microbial Biofilms Grown in Microtiter Plates.' Journal of Microbiological Methods, 72(2), pp. 157-165.

Pelaez, M., Nolan, N. T., Pillai, S. C., Seery, M. K., Falaras, P., Kontos, A. G., Dunlop, P. S. M., Hamilton, J. W. J., Byrne, J. A., O'Shea, K., Entezari, M. H. and Dionysiou, D. D. (2012) 'A Review on the Visible Light Active Titanium Dioxide Photocatalysts for Environmental Applications.' Applied Catalysis B: Environmental, 125, pp. 331-349.

Pérez-Rodríguez, F., Posada-Izquierdo, G. D., Valero, A., García-Gimeno, R. M. and Zurera, G. (2013) 'Modelling survival kinetics of Staphylococcus aureus and Escherichia coli 0157:H7 on stainless steel surfaces soiled with different substrates under static conditions of temperature and relative humidity.' Food Microbiology, 33(2), pp. 197-204.

Pettit, R. K., Weber, C. A., Kean, M. J., Hoffmann, H., Pettit, G. R., Tan, R., Franks, K. S. and Horton, M. L. (2005) 'Microplate Alamar Blue Assay for Staphylococcus epidermidis Biofilm Susceptibility Testing.' Antimicrobial Agents and Chemotherapy, 49(7), pp. 2612-2617.

Priha, O., Raulio, M., Cooke, K., Fisher, L., Hill, C., Hylkinen, S., Kelly, P., Navabpour, P., Ostovarpour, S., Tapani, K., Tattershall, C., Vehviläinen, A.-K., Verran, J. and Storgårds, E. (2015) 'Microbial Populations on Brewery Filling Hall Surfaces - Progress Towards Functional Coatings.' Food Control, 55, pp. 1-11.

Priyadarshini, S., Mainal, A., Sonsudin, F., Yahya, R., Alyousef, A. A. and Mohammed, A. (2020) 'Biosynthesis of TiO2 nanoparticles and their superior antibacterial effect against human nosocomial bacterial pathogens.' Research on Chemical Intermediates, 46(2), pp. 1077-1089.

Rampersad, S. N. (2012) 'Multiple Applications of Alamar Blue as an Indicator of Metabolic Function and Cellular Health in Cell Viability Bioassays.' Sensors 12(9), pp. 12347-12360.

Ratova, M., Sawtell, D. and Kelly, P. J. (2020) 'Micro-Patterning of Magnetron Sputtered Titanium Dioxide Coatings and Their Efficiency for Photocatalytic Applications.' Coatings, 10(1), p. 15. 
Ratova, M., Redfern, J., Verran, J. and Kelly, P. J. (2018) 'Highly Efficient Photocatalytic Bismuth Oxide Coatings and their Antimicrobial Properties under Visible Light Irradiation.' Applied Catalysis B: Environmental, 239, pp. 223-232.

Ratova, M., West, G. T., Kelly, P. J., Xia, X. and Gao, Y. (2015) 'Synergistic Effect of Doping with Nitrogen and Molybdenum on the Photocatalytic Properties of Thin Titania Films.' Vacuum, 114, pp. 205-212.

Ratova, M., Marcelino, R., de Souza, P., Amorim, C. and Kelly, P. (2017) 'Reactive Magnetron Sputter Deposition of Bismuth Tungstate Coatings for Water Treatment Applications under Natural Sunlight.' Catalysts, 7(10), p. 283.

Redfern, J. and Verran, J. (2017) 'Effect of humidity and temperature on the survival of Listeria monocytogenes on surfaces.' Letters in Applied Microbiology, 64(4), pp. 276-282.

Redfern, J. and Enright, M. C. (2020) 'Further understanding of Pseudomonas aeruginosa's ability to horizontally acquire virulence: possible intervention strategies.' Expert Review of Anti-Infective Therapy, 18(6), pp. 539-549.

Redfern, J., Tucker, J., Simmons, L. M., Askew, P., Stephan, I. and Verran, J. (2018a) 'Environmental and Experimental Factors Affecting Efficacy Testing of Nonporous Plastic Antimicrobial Surfaces.' Methods and Protocols, 1(4), p. 36.

Redfern, J., Geerts, L., Seo, J. W., Verran, J., Tosheva, L. and Wee, L. H. (2018b) 'Toxicity and Antimicrobial Properties of ZnO@ZIF-8 Embedded Silicone against Planktonic and Biofilm Catheter-Associated Pathogens.' ACS Applied Nano Materials, 1(4), pp. 1657-1665.

Reid, M., Whatley, V., Spooner, E., Nevill, A. M., Cooper, M., Ramsden, J. J. and Dancer, S. J. (2018) 'How Does a Photocatalytic Antimicrobial Coating Affect Environmental Bioburden in Hospitals?' Infection Control and Hospital Epidemiology, 39(4), pp. 398-404.

Robertson, J. M. C., Sieberg, C. and Robertson, P. K. J. (2015) 'The influence of microbial factors on the susceptibility of bacteria to photocatalytic destruction.' Journal of Photochemistry and Photobiology A: Chemistry, 311, pp. 53-58.

Sadowski, R., Strus, M., Buchalska, M., Heczko, P. B. and Macyk, W. (2015) 'Visible light induced photocatalytic inactivation of bacteria by modified titanium dioxide films on organic polymers.' Photochemical \& Photobiological Sciences, 14(3), pp. 514519.

Scully, J. R. (2020) 'The COVID-19 Pandemic, Part 1: Can Antimicrobial CopperBased Alloys Help Suppress Infectious Transmission of Viruses Originating from Human Contact with High-Touch Surfaces?' Corrosion, 76(6), pp. 523-527.

Silanikove, N. and Shapiro, F. (2012) 'Combined Assays for Lactose and Galactose by Enzymatic Reactions.' In Preedy, V. R. (ed.) Food and Nutritional Components in Focus No. 3: Dietary Sugars: Chemistry, Analysis, Function and Effects. The Royal Society of Chemistry, pp. 395-404. 
Simões, M., Simões, L. C. and Vieira, M. J. (2010) 'A Review of Current and Emergent Biofilm Control Strategies.' LWT - Food Science and Technology, 43(4), pp. 573-583.

Twigg, R. S. (1945) 'Oxidation-Reduction Aspects of Resazurin.' Nature, 155, p. 401.

Vazquez-Sanchez, D., Cabo, M. L. and Rodriguez-Herrera, J. J. (2015)

'Antimicrobial Activity of Essential Oils against Staphylococcus aureus Biofilms.'

Food and Science Technology International, 21(8), pp. 559-570.

Verran, J. (2002) 'Biofouling in Food Processing: Biofilm or Biotransfer Potential?' Food and Bioproducts Processing, 80(4), pp. 292-298.

Verran, J., Redfern, J., Smith, L. A. and Whitehead, K. A. (2010) 'A critical evaluation of sampling methods used for assessing microorganisms on surfaces.' Food and Bioproducts Processing, 88(4), pp. 335-340.

Wilks, S. A., Michels, H. and Keevil, C. W. (2005) 'The Survival of Escherichia coli O157 on a Range of Metal Surfaces.' International Journal of Food Microbiology, 105(3), pp. 445-454.

Wilks, S. A., Michels, H. T. and Keevil, C. W. (2006) 'Survival of Listeria monocytogenes Scott A on Metal Surfaces: Implications for Cross-Contamination.' International Journal of Food Microbiology, 111(2), pp. 93-98.

Wu, M. C., Lin, T. H., Chih, J. S., Hsiao, K. C. and Wu, P. Y. (2017) 'Niobium Doping Induced Morphological Changes and Enhanced Photocatalytic Performance of Anatase $\mathrm{TiO}_{2}$.' Japanese Journal of Applied Physics, 56(4), p. 6.

Yin, H., Li, G., Chen, X., Wang, W., Wong, P. K., Zhao, H. and An, T. (2020) 'Accelerated evolution of bacterial antibiotic resistance through early emerged stress responses driven by photocatalytic oxidation.' Applied Catalysis B: Environmental, 269, p. 118829.

Yoon, Y. H., Lee, S. Y., Gwon, J. G., Cho, H. J., Wu, Q., Kim, Y. H. and Lee, W. H. (2018) 'Photocatalytic Performance of Highly Transparent and Mesoporous Molybdenum-Doped Titania Films Fabricated by Templating Cellulose Nanocrystals.' Ceramics International, 44(14), pp. 16647-16653. 